\title{
Glass Transition Temperature-Composition Relationship of Oxyethylene Copolymers with Chloromethyl/(Ethylthio)methyl, Chloromethyl/(Ethylsulfinyl)methyl, or Chloromethyl/(Ethylsulfonyl)methyl Side Groups
}

\author{
Jong-Chan LEE, ${ }^{\dagger}$ and Morton H. LITT ${ }^{*}$ \\ School of Chemical Engineering and Hyperstructured Organic Materials Research Center, \\ Seoul National University, Seoul 151-742, Korea \\ * Department of Macromolecular Science, Case Western Reserve University, \\ Cleveland, Ohio 44106, U. S. A.
}

(Received July 23, 1999)

\begin{abstract}
The glass transition temperature $\left(T_{\mathrm{g}}\right)$ /composition relationships of three series of copolymers, poly[oxy(chloromethyl)ethylene-co-oxy(ethylthiomethyl)ethylene](CE-ETE), poly[oxy(chloromethyl)ethylene-co-oxy(ethylsulfinylmethyl)ethylene] (CE-ESXE), and poly(oxy(chloromethyl)ethylene-co-oxy(ethylsulfonylmethyl)ethylene) (CE-ESE) were studied. The Fox equation fit the $T_{\rho} /$ composition data only for the CE-ETEs. The densities of CE-ESXE and CE-ESE copolymers were calculated assuming that the densities of the homopolymers were additive at the $T_{\mathrm{g}}$ (reference temperature) and the thermal expansion coefficients were used to calculate densities at room temperature. Those were compared with the experimental values and showed good agreement. The reason for the $T_{\mathrm{g}}$ deviation of the copolymers from the linear additivity was not clear. However it is probably related to the high polarity of the sulfone and sulfoxide groups in the copolymers, and their very strong dipolar interactions.

KEY WORDS Poly(oxyethylene) / Thioether / Sulfoxide / Sulfone / Glass transition Temperature / Density /
\end{abstract}

The glass transition temperatures $\left(T_{\mathrm{g}}\right.$ 's) of copolymers have been correlated by simple additive relationships, such as the Fox equation, ${ }^{1}$ or by consideration of the sequence distribution of monomeric units, by Barton, ${ }^{2}$ Johnston, ${ }^{3}$ Tonelli, ${ }^{4}$ and Couchman. ${ }^{5}$ The Fox equation is based on the assumption that certain properties of copolymers, e.g., specific volume, molar cohesive energy, or chain stiffness are additive combinations of the properties of the corresponding homopolymers. ${ }^{2,3}$ But $T_{\mathrm{g}}$ 's for many copolymer systems exhibit positive or negative deviations from the Fox equation. These deviations were explained to a certain degree by considering sequence distributions and steric effect. ${ }^{2,3}$ However the polar effect on the $T_{\mathrm{g}}$-composition relationships has not been fully explained. Density-composition relations of copolymers have never been studied according to our literature survey. In blends when two polymers are miscible without any strong interaction, the $T_{\mathrm{g}}$-composition curve usually follows the Fox equation. But in blend systems with strong interactions, such as hydrogen bonding or interchain electron donor acceptor complex formation, $T_{\mathrm{g}}$-composition curves show positive deviations from the Fox equation; density-composition curves also show positive deviations. ${ }^{6-12}$

In this paper, the $T_{\mathrm{g}}$-composition and density-composition relationships of three series of copolymers will be discussed. Their syntheses were reported in an earlier paper. ${ }^{13}$

\section{EXPERIMENTAL}

Synthetic routes and acronyms for the homopolymers and copolymers are shown in Scheme $1 .{ }^{13}$ Glass transi-

\footnotetext{
${ }^{\dagger}$ To whom all correspondence should be addressed.
}

tion temperatures $\left(T_{\mathrm{g}}\right.$ 's) were measured using a Du Pont 912 Differential Scanning Calorimeter and obtained from the 2 nd run at a heating rate of $20^{\circ} \mathrm{C} \mathrm{min}-1$ and a nitrogen flow rate of $50 \mathrm{~mL} \mathrm{~min}^{-1}$. Densities were measured by a neutral buoyancy method using a piconometer. ${ }^{14}$ The neutral buoyancy medium was a mixture of tetrachloromethane and hexane. The detailed experimental procedures and film preparation methods for these measurements were described in the previous papers. ${ }^{13,15}$ Table I shows the intrinsic viscosities, $T_{\mathrm{g}}$ 's, and densities of the homopolymers and the copolymers. Densities of poly[oxy(chloromethyl)ethylene-co-oxy(ethylthiomethyl)ethylene] (CE-ETE) copolymers are not listed because reproducible density values of these polymers were not easily obtained. It was very difficult to get freestanding films for the density measurement because they showed liquid like behavior. The numbers at the right side of the copolymer designation indicate the mole percent of sulfur containing monomeric units.

\section{RESULTS AND DISCUSSION}

The three series of copolymers have the common poly[oxy(chloromethyl)ethylene] monomeric unit which contains the chloro group. The second monomer unit of these copolymers contains either an ethylthioether, -sulfoxide or -sulfone group (Scheme 1). Figures 1-3 show density-composition and $T_{\mathrm{g}}$-composition curves of copolymers. The experimental $T_{\mathrm{g}}$ 's of the copolymers were compared with the values (dashed lines in Figures $1-3)$ predicted using the Fox equation ${ }^{1}$

$$
1 / T_{\mathrm{g}}, \mathrm{c}=W_{\mathrm{A}} / T_{\mathrm{g}, \mathrm{A}}+W_{\mathrm{B}} / T_{\mathrm{g}, \mathrm{B}}
$$

where $T_{\mathrm{g}}, \mathrm{c}$ is glass transition temperature of copolymer 


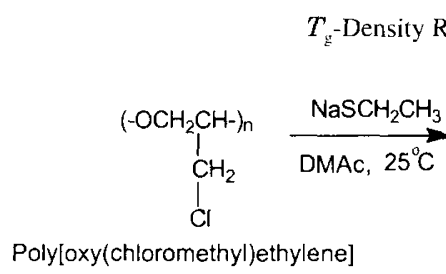

(CE)
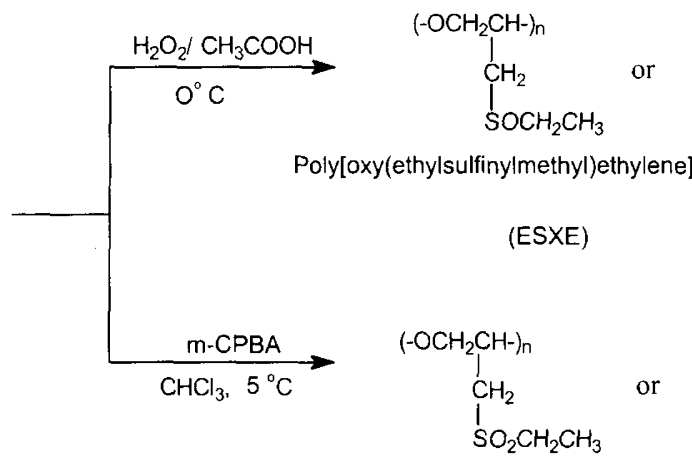

Poly[oxy(ethylsulfonylmethyl)ethylene]

(ESE)

Poly[oxy(ethylthiomethyl)ethylene]

(ETE)

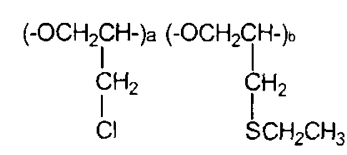

(CE-ETE \#)

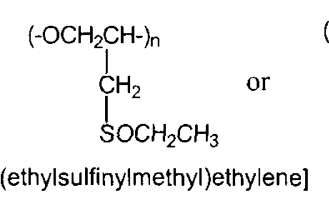

(ESXE)<smiles>CCOS(=O)(=O)CCCCOCCO</smiles>

(CE-ESXE \#)<smiles>CCOS(=O)(=O)CCCCCC(=O)O</smiles>

(CE-ESE \#)

where \# is the mole percent of sulfur containing monomeric unit

Scheme 1.

containing weight fractions $W_{\mathrm{A}}$ and $W_{\mathrm{B}}$ of the monomer units $\mathrm{A}$ and $\mathrm{B}$, for which the homopolymers have glass transitions of $T_{g, A}$ and $T_{g, B}$, respectively.

The Fox equation is based on the assumption that certain properties of a copolymer, e.g., specific volume, molar cohesive energy, or chain stiffness are additive combinations of the properties of the corresponding homopolymers. But this is not the case for many copolymers. Due to sequence distribution and (or) structural effects, $T_{\mathrm{g}}$ 's of copolymers show positive or negative deviations from the Fox equation.

Several authors studied sequence distributions of vinyl copolymers prepared from chemical modifications of vinyl polymers such as poly(vinyl alcohol) (PVA), poly(vinyl acetate) (PVAc), and poly(vinyl chloride) (PVC). ${ }^{16-20}$ When there is no neighboring group interaction and steric hindrance, random copolymers were obtained. ${ }^{17,18}$ The CE-ETE copolymers were obtained within $1 \mathrm{~min}$ in homogeneous $N, N$-dimethylacetamide (DMAc) solution $^{13}$ and there should be no neighboring group interaction and steric effect; a stable intermediate of 5- or 6membered ring structure by the neighboring groups is not possible in the CE substitution and the primary alkyl chloride in $\mathrm{CE}$ is much less sterically hindered than the secondary alkyl chloride in PVC and the secondary alkyl hydroxy group in PVA. Therefore, we think that CE-ETE copolymers are all random, then poly[oxy(chloromethyl)ethylene-co-oxy(ethylsulfinylmethyl)ethylene] (CE-ESXE) and poly(oxy(chloromethyl)ethylene-co-oxy(ethylsulfonylmethyl)ethylene) (CE-ESE) copolymers are also all random. The randomness of the copolymers was also confirmed using ${ }^{13} \mathrm{C}$ NMR by calculating a dyad sequence concentration using an inverse gated decoupling technique. The detailed study on the sequences distributions of thioether and sulfone containing copolymers is in progress. Therefore, only the chemical structure affects the $T_{g}$ deviation of the copolymers from the Fox equation. Here we have three series of copolymers, CE-ETE (chloro and ethylthioether side groups), CEESXE (chloro and ethylsulfinyl side groups) and CEESE (chloro and ethylsulfonyl side groups). The Fox equation shows a good fit with the $T_{\mathrm{g}}$-composition data for CE-ETE (Figure 1). But CE-ESXE and CE-ESE show positive deviations from the Fox equation (Figures 2 and $3)$.

Johnston $^{3}$ rationalized the $T_{\mathrm{g}}$ of many copolymers by considering dyad sequence distributions and the interaction effects between the two monomeric units. Copolymers containing $\mathrm{A}$ and $\mathrm{B}$ monomeric units can have $\mathrm{AA}$, $\mathrm{AB}, \mathrm{BA}$, and $\mathrm{BB}$ dyads. $P_{\mathrm{AA}}$ and $P_{\mathrm{BA}}$ equal the mole fraction of the A component, while $P_{\mathrm{BB}}$ and $P_{\mathrm{AB}}$ equal the mole fraction of $\mathrm{B}$ component for a random copolymer. Using these probabilities, the $T_{g}$ 's of the copolymers are calculated as follows.

$$
\frac{1}{T_{\mathrm{g}, \mathrm{c}}}=\frac{W_{\mathrm{A}} P_{\mathrm{AA}}}{T_{\mathrm{g}, \mathrm{A}}}+\frac{W_{\mathrm{A}} P_{\mathrm{AB}}+W_{\mathrm{B}} P_{\mathrm{BA}}}{T_{\mathrm{g}, \mathrm{AB}}}+\frac{W_{\mathrm{B}} P_{\mathrm{BB}}}{T_{\mathrm{g}, \mathrm{B}}}
$$

where $T_{\mathrm{g}, \mathrm{AB}}$ is the $T_{\mathrm{g}}$ of $\mathrm{AB}$ dyad and the other parameters are same as in the Fox equation. $T_{\mathrm{g}, \mathrm{AB}}$ values have been determined by several techniques. ${ }^{3,21,22}$ In this study, $T_{\mathrm{g}, \mathrm{AB}}$ was calculated using eq 2 . As the parameters in eq 2 are available from Table I, $T_{\mathrm{g}, \mathrm{AB}}$ for each copolymer can be calculated. Average values were obtained for each series of copolymers; they were -37.8 , 22.2 , and $52.7^{\circ} \mathrm{C}, T_{\mathrm{g}, \mathrm{AB}}$ 's for CE-ETE, CE-ESXE, and CEESE, respectively. These values represent the strengths of the chloride-thioether, chloride-sulfoxide, and chlo-

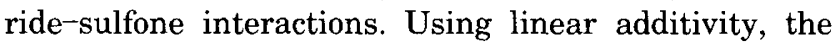


Table I. $T_{\mathrm{g}}$ 's and densities of homopolymers and copolymers

\begin{tabular}{|c|c|c|c|c|c|}
\hline & $\begin{array}{l}\text { Weight } \\
\text { fraction }^{\text {a }}\end{array}$ & $T_{\mathrm{g}}{ }^{\circ} \mathrm{C}$ & Density $^{b}$ & $\begin{array}{l}\text { Calculated } \\
\text { density at } \\
T_{\mathrm{g}}\end{array}$ & $\begin{array}{l}\text { Calculated } \\
\text { density at } \\
25^{\circ} \mathrm{C}\end{array}$ \\
\hline $\mathrm{CE}$ & 0 & $-17^{\mathrm{b}}$ & 1.360 & $1.405^{\mathrm{e}}$ & $1.360^{\mathrm{b}}$ \\
\hline CE-ETE 11 & 0.136 & $-22^{\mathrm{b}}$ & & & \\
\hline CE-ETE 20 & 0.242 & $-27^{\mathrm{b}},-28^{\mathrm{c}}$ & & & \\
\hline CE-ETE 41 & 0.470 & $-35^{\mathrm{b}},-37^{\mathrm{c}}$ & & & \\
\hline CE-ETE 55 & 0.610 & $-44^{b},-43^{c}$ & & & \\
\hline CE-ETE 88 & 0.904 & $-52^{\mathrm{b}},-54^{\mathrm{c}}$ & & & \\
\hline ETE & 1 & $-57^{\mathrm{b}}$ & & & \\
\hline CE-ESXE 20 & 0.266 & $3^{\mathrm{b}},-1.6^{\mathrm{d}}$ & 1.335 & $1.363^{\mathrm{g}}$ & $1.340^{\mathrm{h}}$ \\
\hline CE-ESXE 41 & 0.502 & $11^{\mathrm{b}}, 12^{\mathrm{d}}$ & 1.320 & $1.327^{\mathrm{g}}$ & $1.313^{\mathrm{h}}$ \\
\hline CE-ESXE 55 & 0.639 & $17^{\mathrm{b}}, 20^{\mathrm{d}}$ & 1.300 & $1.305^{\mathrm{g}}$ & $1.297^{\mathrm{h}}$ \\
\hline CE-ESXE 88 & 0.914 & $31^{b}, 33^{d}$ & 1.265 & $1.262^{\mathrm{g}}$ & $1.264^{\mathrm{i}}$ \\
\hline ESXE & 1 & $36^{\mathrm{b}}$ & 1.252 & $1.249^{\mathrm{f}}$ & $1.252^{\mathrm{b}}$ \\
\hline CE-ESE 20 & 0.289 & $11^{\mathrm{b}}, 7^{\mathrm{d}}$ & 1.368 & $1.389^{\mathrm{g}}$ & $1.374^{\mathrm{h}}$ \\
\hline CE-ESE 41 & 0.532 & $24^{\mathrm{b}}, 28^{\mathrm{d}}$ & 1.378 & $1.376^{\mathrm{g}}$ & $1.375^{\mathrm{h}}$ \\
\hline CE-ESE 55 & 0.662 & $40^{b}, 38^{d}$ & 1.394 & $1.369^{\mathrm{g}}$ & $1.373^{\mathrm{i}}$ \\
\hline CE-ESE 88 & 0.923 & $53^{\mathrm{b}}, 54^{\mathrm{g}}$ & 1.385 & $1.355^{\mathrm{g}}$ & $1.362^{\mathrm{i}}$ \\
\hline ESE & 1 & $57^{\mathrm{b}}$ & 1.360 & $1.351^{\mathrm{f}}$ & $1.360^{\mathrm{b}}$ \\
\hline
\end{tabular}

$T_{\mathrm{g}}$ 's of the copolymers at equal molar composition of both component should be $-37,9.5$, and $20^{\circ} \mathrm{C}$ for CE-ETE, CE-ESXE, and CE-ESE, respectively; these values are for copolymers in which the cross interaction energies are the mean of the homo interaction energies. Little, if any, specific interaction between chloride and thioether groups is expected. However the specific interaction between chloride and sulfoxide groups is quite large, and that between chloride and sulfone groups is even larger. This can be seen from the temperature differences between the $T_{\mathrm{g}, \mathrm{AB}}$ calculated from eq 2 and the $T_{\mathrm{g}}$ 's of $50 / 50$ weight percent copolymers calculated using the linear additivity rule; the differences for CE-ETE, CE-ESXE, and CE-ESE are $0.8,12.7$, and $32.7^{\circ} \mathrm{C}$, respectively.

$T_{\mathrm{g}}$-composition curves of CE-ETE, CE-ESXE, and CEESE calculated from the Johnston equation, eq 2, using the best fit $T_{\mathrm{g}, \mathrm{AB}}$ values are shown in Figures $1-3$. The $T_{\mathrm{g}}$-composition curve for CE-ETE from the Johnston equation was almost identical with that from the Fox equation.

Density-composition curves of CE-ESXE and CE-ESE copolymers show the same trend as $T_{\mathrm{g}}$-composition curves. This phenomenon can be explained by considering the thermal expansion of polymers.

It has been known that the free volumes of most polymers at their $T_{\mathrm{g}}$ 's are almost identical. ${ }^{23}$ The homo- and copolymers in this study have the same backbones, so the backbones have similar flexibility. Therefore we can assume that the free volumes at $T_{\mathrm{g}}$ in all the homo- and copolymers are very close. The polymer at its $T_{\mathrm{g}}$ is at its reference state. The higher $T_{\mathrm{g}}$ 's in the sulfoxide and sulfone are then due to their strong polar interactions that decrease the free volume at a given temperature. With this postulate, the copolymer densities at $T_{\mathrm{g}}$ should be a linear combination of the homopolymer densities at $T_{\mathrm{g}}$.
The system is then extrapolated to room temperature to generate calculated densities that can be compared to the measured values.

Polymer volumes increase with increasing temperature. The volume thermal expansion coefficient, denoted $\alpha$, is defined ${ }^{24}$ as

$$
\alpha \equiv \frac{V-V_{0}}{V_{0} \Delta T}
$$

where $V_{0}$ is the initial volume and $V$ is the volume after a small change in temperature $\Delta T ; \alpha$ is assumed constant over the range of $\Delta T$. The expansion coefficients of a polymer in the rubbery and glassy states are different. The literature value for the thermal expansion coefficient of rubbery poly[oxy(chloromethyl)ethylene], $\mathrm{CE}$, is $7.7 \times 10^{-4} \mathrm{~cm}^{3} \mathrm{~cm}^{-3} \mathrm{~K}^{-1}{ }^{25}$ No glassy expansion coefficient could be found. The thermal expansion coefficients of glassy polymers, such as polystyrene, poly(vinyl acetate), poly(methyl methacrylate), poly(ethylene terephthalate) (PET), and so on, are not very different and average around $2.0 \times 10^{-4} \mathrm{~cm}^{3} \mathrm{~cm}^{-3} \mathrm{~K}^{-1.24} \mathrm{Al}-$ though the thermal expansion coefficients of copolymers in this study may not be the same as that of $\mathrm{CE}$, they should not be very different because the copolymers have very similar chemical structures. From the above considerations we postulate that the thermal expansion coefficients of the rubbery and glassy copolymers are 7.7 $\times 10^{-4} \mathrm{~cm}^{3} \mathrm{~cm}^{-3} \mathrm{~K}^{-1}$ and $2.0 \times 10^{-4} \mathrm{~cm}^{3} \mathrm{~cm}^{-3} \mathrm{~K}^{-1}$, respectively.

We can then calculate the densities of the homopolymers, CE, ESXE, and ESE at $T_{\mathrm{g}}$ using eq 4 or 5 


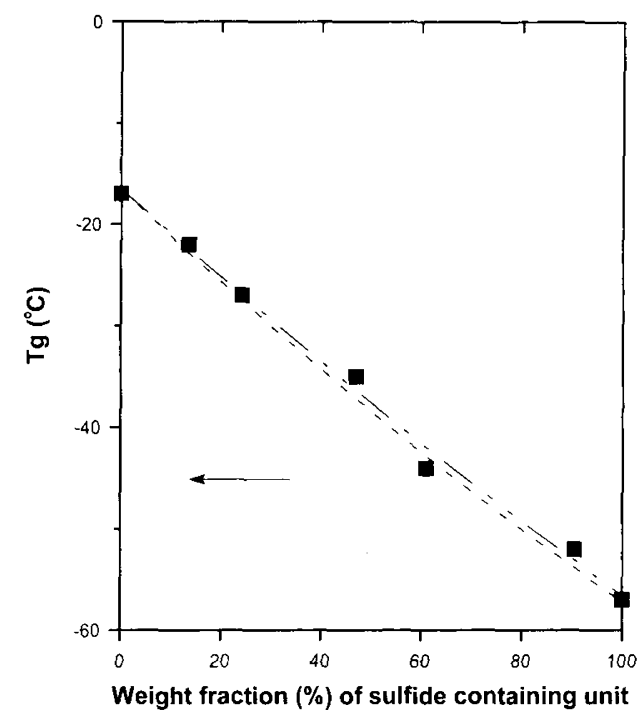

Figure 1. Glass transition temperatures $(\square)$ and densities $(\mathbf{)})$ of CE-ETE ; Fox equation, eq 1, (- - - ), Johnston equation, eq $2,(-\cdots,-$.

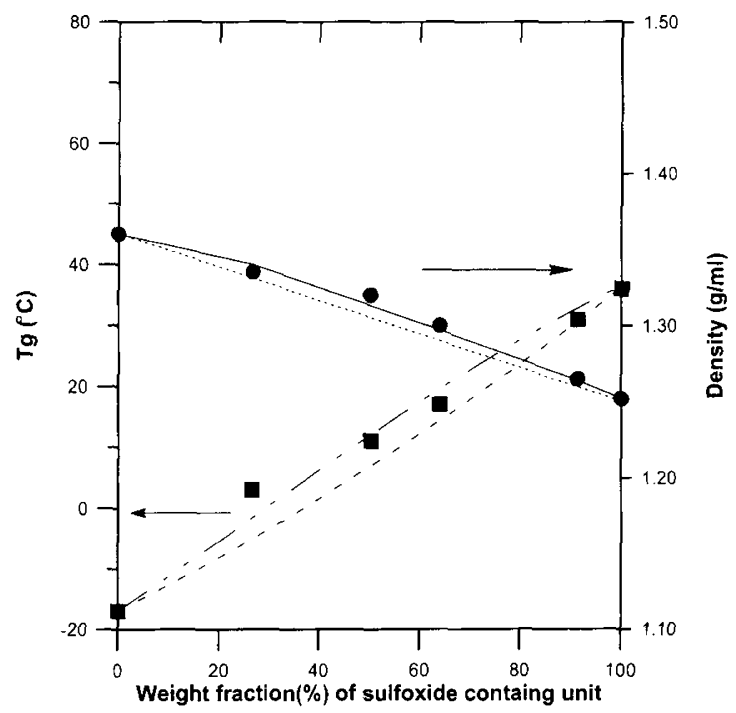

Figure 2. Glass transition temperatures $(\square)$ and densities $(\mathbf{O})$ of CE-ESXE ; Fox equation, eq 1, (- - ) Johnston equation, eq $4,(--)$, calculated density from $T_{\mathrm{g}}$, eq 6 and 7 or $8,(-$

$$
\begin{aligned}
& d^{\prime}=\frac{d}{1+\alpha_{\mathrm{G}}\left(T_{\mathrm{g}}-\overline{25)}\right.} \\
& d^{\prime}=\frac{d}{1-\alpha_{\mathrm{L}}\left(25-T_{\mathrm{g}}\right)}
\end{aligned}
$$

where $d$ is the density obtained at room temperature, $d^{\prime}$ is the calculated density of homopolymer at $T_{\mathrm{g}}, \alpha_{\mathrm{G}}(2.0$ $\times 10^{-4} \mathrm{~cm}^{3} \mathrm{~cm}^{-3} \mathrm{~K}^{-1}$ ) is the glassy bulk thermal expansion coefficient, and $\alpha_{\mathrm{L}}\left(7.7 \times 10^{-4} \mathrm{~cm}^{3} \mathrm{~cm}^{-3} \mathrm{~K}^{-1}\right)$ is the rubbery bulk thermal expansion coefficient.

The density of copolymers at $T_{\mathrm{g}}$ can be calculated according to eq 6 . Here we assume that the density of the copolymers at $T_{\mathrm{g}}$ follows the linear additivity rule

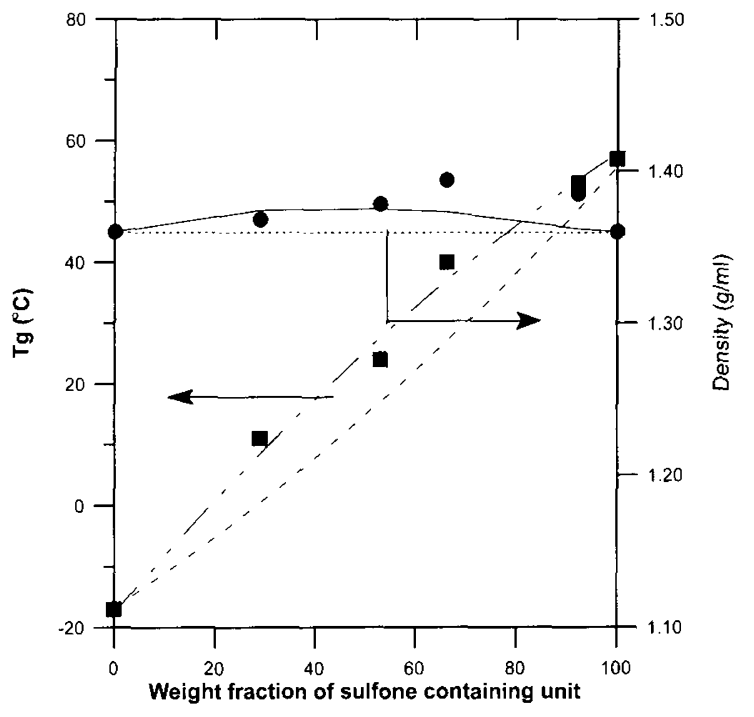

Figure 3. Glass transition temperatures ( $\square$ ) and densities $(O)$ of CE-ESE ; Fox equation, eq 1, (- - - ), Johnston equation, eq $2,\left(--\frac{-}{-}\right.$, calculated density from $T_{g}$, eq 6 and 7 or $8,(--$ $\longrightarrow$, calculated density from linear combination (--.....

$$
d^{\prime \prime}{ }_{T_{\mathrm{g}}}=W_{1} d^{\prime}{ }_{1}+W_{2} d_{2}^{\prime}
$$

$d^{\prime \prime} T_{\mathrm{g}}$ is the calculated density of a copolymer at $T_{\mathrm{g}}, W_{1}$, and $W_{2}$ are the weight fractions of monomeric units 1 and $2, d_{1}^{\prime}$ and $d_{2}^{\prime}$ are the densities of the corresponding homopolymers at their $T_{\mathrm{g}}$ 's.

Finally the copolymer density at room temperature can be calculated using eq 7 , for a glassy polymer, or eq 8 , for a rubbery polymer

$$
\begin{aligned}
& d_{\mathrm{G}, \mathrm{RT}}^{\prime \prime}=\frac{d_{T_{\mathrm{g}}}^{\prime \prime}}{1-\alpha_{\mathrm{G}}\left(T_{\mathrm{g}}-25\right)} \\
& d_{\mathrm{L}, \mathrm{RT}}^{\prime \prime}=\frac{d_{T_{\mathrm{g}}}^{\prime \prime}}{1+\alpha_{\mathrm{L}}\left(25-T_{\mathrm{g}}\right)}
\end{aligned}
$$

where $d_{\mathrm{G}, \mathrm{RT}}^{\prime \prime}$ and $d_{\mathrm{L}, \mathrm{RT}}^{\prime \prime}$ are the calculated densities of the glassy and rubbery copolymers at room temperature. The calculated densities of the polymers at $T_{\mathrm{g}}$ and room temperature are listed in Table I.

$T_{\mathrm{g}}$ 's of CE-ESXEs and CE-ESEs show positive deviations from the Fox equation (Figures 2 and 3). For this reason, the densities of these polymers were calculated using experimental $T_{\mathrm{g}}$ values. Most of the calculated densities show very good agreement with the experimental densities (Figures 2 and 3). The density deviations from linear additivity can be simply explained by the volume changes as the copolymers are brought to room temperature from the $T_{\mathrm{g}}$ reference state.

The calculated densities of CE-ESE 55 and CE-ESE 88 show relatively large deviation from the experimental values. This may be due to volume relaxation. ${ }^{23,26-28}$ $T_{\mathrm{g}}$ 's are measured at fast heating rate $\left(20^{\circ} \mathrm{C} \mathrm{min}^{-1}\right)$ after quenching the melted sample, so there is no volume relaxation. Density measurements were done using polymer films that were dried under vacuum at $130^{\circ} \mathrm{C}$ for 3 days, slowly cooled to room temperature and stored at room temperature at least overnight. Polymer in the 
rubbery state relaxes to its equilibrium volume immediately. However polymer in the glassy state relaxes slowly and the relaxation time (the time needed to reach its equilibrium volume) increases exponentially with $T_{\mathrm{g}}$ $-T$. Using a kinetic theory of the glass transition, Eisenberg calculated the volume relaxation time of polystyrene, whose $T_{\mathrm{g}}$ is $100^{\circ} \mathrm{C}$, at various temperatures. ${ }^{23}$ The volume relaxation time of polystyrene was $0.01 \mathrm{~s}$ at 100 ${ }^{\circ} \mathrm{C}, 1 \mathrm{~s}$ at $95^{\circ} \mathrm{C}, 120 \mathrm{~s}$ at $90^{\circ} \mathrm{C}, 5 \mathrm{~h}$ at $85^{\circ} \mathrm{C}, 60 \mathrm{~h}$ at $79^{\circ} \mathrm{C}$, and 1 year at $77^{\circ} \mathrm{C}$. These results show that the volume relaxation times of the polymers at $T_{\mathrm{g}}$ to $T_{\mathrm{g}}-10^{\circ} \mathrm{C}$ are of the order of seconds, while those of polymers at $T_{\mathrm{g}}-15$ to $T_{\mathrm{g}}-21$ are of the order of hours. However polymers more than $23^{\circ} \mathrm{C}$ below $T_{\mathrm{g}}$ cannot reach equilibrium volume in less than a year. This rationale may explain why CE-ESE 55 and CE-ESE 88 whose $T_{\mathrm{g}}$ 's are $40^{\circ} \mathrm{C}$ and 53 ${ }^{\circ} \mathrm{C}$, respectively show densities higher than the calculated values, while ESE, whose $T_{\mathrm{g}}$ is $57^{\circ} \mathrm{C}$, probably did not undergo much volume relaxation. Alternatively, it may due to the strong A B interactions that were noted in the $T_{\mathrm{g}}$ curves. This could increase the densities over those calculated assuming linear additivity of the homopolymer properties.

The density/composition changes of CE-ESXE and CEESE copolymers are explained by the thermal expansion or contraction of the polymers from the $T_{\mathrm{g}}$ standard state, but the $T_{\mathrm{g}}$ deviation is not fully understood. As all the copolymers have random structures, there is no sequence effect. However a simple trend was observed; as the polarity of one of the monomeric units increased from thioether to sulfoxide then finally to sulfone, the $T_{\mathrm{g}}$ deviation from the Fox equation went from zero, to slightly positive, to finally very positive. Normally $T_{\mathrm{g}}$ 's of polymers are affected by both polar and steric factors. In these copolymers, as the side chains are attached every three atoms in the backbone, steric factors should be very small but the polar interactions could affect the copolymer $T_{\mathrm{g}}$ 's. CE-ETEs contains two kinds of weakly polar side groups, chloro and ethylthioether groups, whose dipole moments are 1.50 and 1.86 Debye, respectively. ${ }^{29}$ These copolymers have little, if any, excess polar interactions or steric hindrance which can affect the mobility of the polymer chains ; the $T_{\mathrm{g}}$ 's followed the Fox equation very well. CE-ESXEs and CE-ESEs contains the very polar sulfoxide and sulfone side groups ; their $T_{\mathrm{g}}$ 's showed positive deviations. The deviations might be due to strong dipole-dipole interaction and/or weak hydrogen bonding between the proton in the chloromethyl group and the electron rich oxygen in the sulfone or sulfoxide group. As the sulfone group is more polar than sulfoxide group (the dipole moments of sulfoxide and sulfone groups are 3.93 and 4.49 Debyes, respectively), ${ }^{29}$ stronger interactions in CE-ESE than those in CE-ESXE are expected, and the $T_{\mathrm{g}}$ deviations in the CE-ESEs were larger than those in the CE-ESXEs.

\section{CONCLUSIONS}

Density deviations of the CE-ESXE and CE-ESE copolymers from the linear additivity rule were explained by the thermal expansion or contraction from the $T_{\mathrm{g}}$, the reference state. The densities of the copolymers were calculated using the thermal expansion or contraction coefficient from the density at $T_{\mathrm{g}}$, and compared with the experimental values. The fit was very good except for CE-ESE 55 and CE-ESE 88. Volume relaxation may have occurred in these two copolymers during film preparation since their $T_{\mathrm{g}}$ 's are just above room temperature.

The $T_{\mathrm{g}}$ deviations of copolymers were not completely understood, though a simple trend was observed. The polarity of the sulfur containing monomeric unit in the copolymer increases from thioether to sulfoxide to sulfone. The deviation from the Fox equation in the $T_{\mathrm{g}}-$ composition curves goes from zero, to slightly positive, to finally very positive. The Johnston equation could fit the data with the cross $T_{\mathrm{g}, \mathrm{AB}}$ term increasing compared to the linearly additive $T_{\mathrm{g}, \mathrm{AB}}$ as the polarity of the sulfur containing residue increased. This implies that there are specific interactions between the chloromethyl and sulfoxide or sulfone containing side groups. However, we do not know what form the interactions take.

Acknowledgment. Financial support of this work by Edison Innovation Corporation (EPIC) and Allied-Signal Corp. is gratefully acknowledged. This work has in part been supported by Korea Science and Engineering Foundation through Hyperstructured Organic Materials Research Center.

\section{REFERENCES}

1. T. G. Fox, Bull. Amer. Phys. Soc., 1, 123 (1956).

2. J. M. Barton, J. Polym. Sci., Part C, 30, 573 (1970).

3. N. W. Johnston, J. Macromol. Sci.-Rev. Macromol. Chem., C 14, 215 (1976).

4. A. E. Tonelli, Macromolecules, 7, 632 (1974).

5. P. R. Couchman, Macrmolecules, 15, 770 (1982).

6. J. M. Rodriguez-Parada and V. Percec, Macromolecules, 19, 55 (1986).

7. J. S. Chiou and D. R. Paul, J. Appl. Polym. Sci., 34, 1037 (1987).

8. C. T. Landry and D. M. Teegarden, Macromolecules, 24, 4310 (1991).

9. F. Y. Xu and J. C. W. Chien, Macromolecules, 27, 6589 (1994).

10. P. Pedrosa, J. A. Pomposo, E. Calahorra, and M. Cortazar, Macromolecules, 27, 102 (1994).

11. S. M. Low, S. H. Goh, and S. Y. Lee, Macromolecules, 27, 3764 (1994).

12. A. M. de Ilarduya, J. J. Iruin, and M. J. Fernandez-Berridi, Macromolecules, 28, 3707 (1995).

13. J.-C. Lee, M. H. Litt, and C. E. Rogers, J. Polym. Sci., Polym. Chem. Ed., 36, 793 (1998).

14. J. P. Runt, "Encyclopedia of Polymer Science and Engineering," H. Mark, N. M. Bikales, C. E. Overberger, and G. Menges, Ed., John Wiley \& Sons, Inc., New York, N.Y., 1986, Vol. 4, p 458.

15. J.-C. Lee, M. H. Litt, and C. E. Rogers, J. Polym. Sci., Polym. Phys. Ed., 36, 75 (1998).

16. E. Maréchal, "Comprehensive Polymer Science," S. A. Allen, Ed., Pergamon Press, New York, N.Y., 1989, Vol. 6, p 1.

17. T. N. Bowmer and A. E. Tonelli, J. Polym. Sci., Polym. Phys. Ed., 24, 1681 (1986).

18. W. Mormann and T. Wagner, J. Polym. Sci., Polym. Chem. Ed., 33, 1119 (1995).

19. N. Pourahmady and P. I. Bak, J. Macromol. Sci.-Pure Appl. Chem., A 31, 185 (1994).

20. J. C. Bevington and G. Thorpe, Makromol. Chem., Macromol. Symp., 20/21, 1 (1988).

21. N. W. Johnston, Macromolecules, 6, 453 (1973).

22. N. W. Johnston, J. Macromol. Sci.-Chem., A 7, 531 (1973).

23. J. E. Mark, A. Eisenberg, W. W. Graessley, L. Mandelkern, E. 
T. Samulski, J. L Koenig, and G. D. Wignall, "Physical Properties of Polymers," 2nd ed, Am. Chem. Soc., Washington, D. C., 1993.

24. E. V. Thomson, "Encyclopedia of Polymer Science and Engineering" 2nd ed, H. F. Mark, N. M. Bikales, C. G. Overberger, and G. Menges, Ed., John Wiley, New York, N.Y., 1989, Vol. $16, \mathrm{p} 771$.

25. J. R. Richards, Diss. Abs., 22, 1029 (1961).

26. J. J. Aklonis and W. J. MacKnight, "Introduction to Polymer Viscoelasticity," 2nd ed, John Wiley, New York, N.Y., 1983, p
57.

27. L. C. E. Struik, "Encyclopedia of Polymer Science and Engineering," 2nd ed, Mark, H. F., H. F. Mark, N. M. Bikales, C. G. Overberger, and G. Menges, Ed., John Wiley, New York, N.Y., 1985, Vol. 1, p 595.

28. A. J. Kovacs, J. J. Aklonis, J. M. Hutchinson, and A. R. Ramos, J. Polym. Sci. Polym. Phys. Ed., 17, 1079 (1979).

29. "CRC Handbook of Chemistry and Physics," 60th ed, R. C. Weast, Ed., CRC Press, Cleveland, OH, 1979, p E64. 